\title{
Influence of the different pod positions and screening methods on soybean pod shattering
}

\author{
Ayda KrisnawatI ${ }^{1,2}$, Andy Soegianto ${ }^{1}$, Budi Waluyo ${ }^{1}$, Mochammad Muchlish Adie ${ }^{2}$, \\ Kuswanto Kuswanto ${ }^{1, *}$ \\ ${ }^{1}$ Dept. of Agronomy, Faculty of Agriculture, Brawijaya University, \\ Malang, Indonesia, \\ ${ }^{2}$ Dept. of Plant Breeding, Indonesian Legume and Tuber Crops Research Institute, \\ Malang, Indonesia \\ *Corresponding Author: kuswantoas@ub.ac.id
}

\begin{abstract}
Pod shattering is one of the major soybean constraints in the soybean production centers, particularly in the tropics. The screening for pod shattering resistance of 16 genotypes was carried out using detached and undetached pod methods on the three different pod positions on the stem. The field research was arranged in a randomized block design, during the dry season in Banyuwangi, Indonesia. The shattering evaluation was conducted in the laboratory using the ovendry method. The screening methods to investigate the pod shattering resistance of each genotype consisted of the detached pod (DP), undetached pod (UDP), and undetached whole-stem method (UWS). The result showed that the detached pod method (DP) resulted in a higher average podshattering percentage (15\%) than the undetached pod methods (UDP and UWS, $13 \%$ and $11 \%$, respectively). Nevertheless, the detached pod and undetached pod methods provide a consistent result for the evaluation of pod shattering resistance, showed by their correlation coefficients (DP and UDP, $\mathrm{r}=0.98^{* *}$; DP and UWS, $\mathrm{r}=0.98^{* *}$, UDP and UWS, $\left.\mathrm{r}=0.99^{* *}\right)$. The detached pod with the oven-dry method was suggested to be used for screening of pod shattering resistance. This method enables to screen genotypes in greater numbers, provides a homogeneous selection pressure and environmental condition. Pods at the upper part of the stem were more resistant to shattering than those pods in the middle part and lower part. The pod length, seed length, seed weight, pod wall weight to the pod weight ratio, and weight of 25 seeds appeared to be the significant indicators for pod shattering resistance. The shattering evaluation resulted in five soybean genotypes (Anj/G100H-28, Anj/G100H-44, Anj/Rjbs-304, Anj/Rjbs-30, and Detap 1) with consistent resistance to pod shattering based on the three methods. These genotypes can be used as donor parents in the breeding program for pod shattering resistance.
\end{abstract}

Keywords: Detached pod; pod dehiscence; stepwise regression; undetached pod; validation. 


\section{Introduction}

Soybean is a potential source of protein used as a raw material for the food industry, such as for tempeh and tofu production. Soybean production can be optimized simultaneously by increasing productivity as well as saving the yield losses, such as due to pod shattering. The pod-shattering trait becomes an important concern since it caused considerable yield losses (Yue et al., 2006; Bhor et al. 2014). The labor scarcity can delay the harvesting, thus will increase the possibility of pod shattering (Tukamuhabwa et al., 2002).

Pod shattering is a complex process determined by both genetic and environmental factors. On soybean, pod shattering can be defined as a process of opening the pod wall after maturity which causes seeds to be released (Bhor et al., 2014). Pod shattering on soybean can be measured based on the shattering incidence or shattering severity (Krisnawati et al., 2020). On other crops, such as canola, Cavalieri et al., (2014) distinguished between the pod drop and pod shatter which all contributed to the preharvest losses.

The investigation on the factors affecting pod shattering resistance from the aspects of pod morphology and anatomy, biochemical factors, as well as the genetic constitution has been conducted in various plants (Funatsuki et al., 2014; Hradilová et al., 2017; Zhang et al., 2018; Liu et al., 2019). In soybean, the studies on the genetic control of pod shattering resistance resulted in varying results (Tukamuhabwa et al., 2002; Agrawal et al., 2003; Mohammed et al., 2014; Bhor et al., 2014). The factors affecting pod shattering resistance have been studied using different approaches. Soybean with a small pod, less width, and low volume/weight of seed was reported to be tolerant to pod shattering (Bara et al., 2013). In other studies, pod shattering was negatively correlated with the pod diameter (Adeyeye et al., 2014) and the number of seeds per pod (Kataliko et al., 2019). Also, pod shattering resistance was negatively and significantly correlated with the thickness and length of the bundle cap on the dorsal side of the pod and the thickness of the pod (Tiwari \& Bhatia, 1995). A study on the 591 of the F5 soybean population found that the pod length was one of the important traits contributing to the pod shattering resistance (Krisnawati et al., 2019). Further study showed that pod shattering resistance was positively and significantly correlated with the length of the dorsal and ventral side of the soybean pod, total pod weight, and seed size (Krisnawati et al., 2020).

The pod shattering resistance was also affected by the maturity date, harvest delay, soil moisture, temperature, rainfall, and environmental relative humidity (Philbrook \& Oplinger, 1989; Tukamuhabwa et al., 2002; Zhang \& Bellaloui, 2012). The study on the effect of irrigation on podshattering showed that non-irrigated soybean shattered faster than irrigated soybean. Furthermore, late-maturing pods tended to have a low shattering, most likely due to lower temperatures in the time of maturity (Zhang \& Boahen, 2010).

The pod development in soybean is initiated by the process of the formation of the first flower at any node in the plant (Fehr \& Caviness, 1977). The duration of flower and pod formation varies between cultivars (Zheng et al., 2003; Egli \& Bruening, 2006). The orientation and characteristics of the soybean pod are interesting studies concerning the pod shattering trait. Saitoh et al. (1998) 
reported that soybean flowering of cultivated and wild-type plants proceeded from the basal order racemes to the upper order racemes. These findings suggest the existence of the difference of maturity and pod shattering between pods at different node positions on the soybean plant.

In our previous experiments using the detached sample pods, it showed that the highest percentage of the shattered pods was in the lower part of the stem, followed by the middle and upper part, respectively. In this study, we would like to clarify the differences in the pod shattering resistance between the detached and undetached pods method, as well as the important variable of pod and seed characters that determine the shattering resistance. Therefore, this research aimed to evaluate the effect of the pod position on the plant and the screening method in the pod shattering resistance and to investigate the determinant factors in the shattering resistance based on the seed and pod morphological characters.

\section{Materials and methods}

\subsection{Research materials}

The materials consisted of fourteen soybean genotypes derived from the selected lines of the crossing between pod-shatter resistant cultivar (Anjasmoro) with high yielding genotypes, and two check cultivars. The check cultivars are new improved varieties with characteristics of high yielding and pod-shatter resistant (Detap 1) and high yielding, large seed size but susceptible to pod shattering (Dega 1). The genotypes used in this study were from the F8 generation, were derived using a pedigree selection method.

\subsection{Field evaluation}

The field experiment was conducted in Banyuwangi Regency, East Java Province (Indonesia), which is located at the $8^{\circ} 22^{\prime} 44.4^{\prime \prime}$ South Latitude and $114^{\circ} 8^{\prime} 45.6^{\prime \prime}$ East Longitude. The location elevation was $168 \mathrm{~m}$ above sea level with the climate type was C2 (Oldeman), and the soil type was Entisol. The minimum and maximum temperatures were $23^{\circ} \mathrm{C}$ and $30^{\circ} \mathrm{C}$, respectively. The relative humidity was $82.5 \%$. The field research was conducted during the dry season (July to October) 2019, arranged in a randomized block design with four replications. The research location was in the lowland paddy field after rice planting under zero-tillage conditions. Each genotype was planted in a plot size of $2 \mathrm{~m} \times 4.5 \mathrm{~m}$ with a planting distance of $40 \mathrm{~cm} \times 15 \mathrm{~cm}$. Plants were fertilized at planting with $50 \mathrm{~kg} \mathrm{ha}^{-1}$ Urea, $100 \mathrm{~kg} \mathrm{ha}^{-1} \mathrm{SP} 36$, and $75 \mathrm{~kg} \mathrm{ha}^{-1} \mathrm{KCl}$. The weeds, pests, and disease were optimally controlled.

\subsection{Screening for pod shattering resistance in the laboratory}

The evaluation for pod shattering resistance of each genotype was done in the laboratory. When the plant reached full maturity (R8 phase, $95 \%$ of the pods have turned brown/reached their mature 
pod color), thirty plants were randomly sampled from each combination of genotype and replication and dried at room temperature for three days. After that, each set of the thirty sample plants was divided into three equal sub-sets consisting of ten plants for pod-shattering evaluation using three different evaluation methods. The screening methods to investigate the pod shattering resistance of each genotype consisted of the detached pod, undetached pod, and undetached wholestem method.

In the detached pod (DP) method: ten sample plants from each combination of genotype and replication were used. Each plant was divided into three parts i.e., upper part, middle part, and lower part. Thirty pods were randomly detached from each part of ten plants and were placed in a Petri dish $((\varnothing=15 \mathrm{~cm})$, and then kept in an oven for six days according to the oven-dry method by Krisnawati \& Adie (2017a).

In the undetached pod (UDP) method: a plant was randomly chosen from ten sample plants from each combination of genotype and replication. The plant was divided into three parts i.e. upper part, middle part, and lower part. Each part was placed in a brown paper bag and then kept in an oven for six days according to the oven-dry method by Krisnawati \& Adie (2017a).

In the undetached pod on whole stem (UWS) method: a plant was randomly chosen from ten sample plants from each combination of genotype and replication. The plant was divided into three parts (upper part, middle part, and lower part), which were marked with black ink. The pods were still attached to the stem. The whole stem then was placed in a brown paper bag and then kept in an oven for six days according to the oven-dry method by Krisnawati \& Adie (2017a).

The calculation of the number of shattered pods on each method was made for each part. The shattering percentage was counted as the number of shattered pods per total number of pods expressed as a percentage. The pod-shattering degree was based on the AVRDC guidelines/method (1979).

The observations were made on the pod shattering percentage, pod morphological characters, and seed morphological characters. The pod morphological characters consisted of pod length (PLG), pod width (PWD), width at mid part (PHG), and pod thickness (PTH). The measurement of the pods was according to Bara et al. (2013). The seed morphological characters consist of seed length (SLG), seed width (SWD), dan seed thickness (STH) (Kibar \& Ozturk, 2008). In addition, the pod wall weight to pod weight ratio (PTT) and the seed weight to pod weight ratio (STT) was determined. The weight of 25 seeds (WSE) was measured.

The backward stepwise regression (using the Minitab ver. 17 statistical software) was used for selecting the most significant variables as the determinant factors of pod shattering resistance based on the data of seed and pod morphological characters. The Pearson correlation (using the Minitab ver. 17 statistical software) was used to measure the strength of the association between detached pod (DP and UDP) and undetached pod (UWS) methods. The relationship among podshattering with pod and seed characters was investigated using the GGEBiplotGUI package in $\mathrm{R}$ software (RStudio Team, 2020). 


\section{Results}

\subsection{The detached pod (DP) method}

The pod shattering resistance of soybean genotypes differed between pod positions on the stem (Table 1). All pods from three different positions on the stem did not shatter at the oven temperature of $30^{\circ} \mathrm{C}$. The variation in pod shattering showed at the oven temperature of $50^{\circ} \mathrm{C}$ and $60^{\circ} \mathrm{C}$. At $60^{\circ} \mathrm{C}$, the shattering percentage of pods in the upper part of the stem ranged from $0-$ $100 \%$. The degree of resistance was grouped into three very resistant genotypes, eleven resistant genotypes, and one moderate genotype, and one very susceptible genotype. In the middle part, most of the genotypes were very resistant at the temperature of $50^{\circ} \mathrm{C}$. The variation of pod shattering showed at $60^{\circ} \mathrm{C}$ with the range of shattering from $2-100 \%$. The degree of resistance consists of ten resistant genotypes, five moderate genotypes, and one very susceptible genotype.

The average of pod-shattering from sixteen genotypes at the upper, middle, and lower parts of the stem was presented in Figure 1a. The pod-shattering of pods in the lower part of the stem showed a high variation in the degree of resistance. The shattering degree of all genotypes at $40^{\circ} \mathrm{C}$ and $50^{\circ} \mathrm{C}$ was similar, except for Grbg/Anj-2 and Dega 1 which showed very susceptibility to shattering. At the end of observation $\left(60^{\circ} \mathrm{C}\right)$, the sixteen genotypes were classified into five resistant genotypes, eight moderate genotypes, one susceptible genotype, and two very susceptible genotypes. When we calculate the total average of pod-shattering from upper, middle, and lower parts at $60{ }^{\circ} \mathrm{C}$, hence five genotypes showed high consistent resistance (very resistant and resistant). The example of shattered pods from different pod positions derived from the DP method was presented in Figure 2a.

\subsection{The undetached pod (UDP) method}

The UDP method provides a lower average percentage of pod shattering than those of the DP method (Table 2). All genotypes were resistant at the oven temperature of $30^{\circ} \mathrm{C}$ and $40^{\circ} \mathrm{C}$, and the pod shattering showed consistency for all pods from the upper, middle, and lower parts. At $50^{\circ} \mathrm{C}$, all genotypes still showed very resistance to shattering, except Dega 1 (very susceptible) and Grbg/Anj-2 (moderate to very susceptible). The pod-shattering percentage of the upper, middle, and lower parts at $60^{\circ} \mathrm{C}$ ranged from $0-100 \%, 2-100 \%$, and $2-100 \%$, respectively. The average of pod-shattering from sixteen genotypes at the upper, middle, and lower parts of the stem was presented in Figure 1b.

In the upper part, the pod shattering of 16 genotypes at $60^{\circ} \mathrm{C}$ was categorized into ten very resistant genotypes, four resistant genotypes, one susceptible genotype, and one very susceptible genotype. The change in the shattering resistance showed in the pods from the middle part. There were no more genotypes that reacted very resistant at $60^{\circ} \mathrm{C}$. It turned into resistant (twelve genotypes), moderate (two genotypes), susceptible (one genotype), and very susceptible (one genotype). The pods in the lower part showed a higher percentage of shattering than those in the 
upper and middle parts. In this part, the shattering degree of all genotypes was six resistant genotypes, eight moderate genotypes, and two very susceptible genotypes. The total average of pod-shattering from the upper, middle, and lower parts at $60^{\circ} \mathrm{C}$ showed six genotypes that showed high consistent resistance (very resistant and resistant). The example of shattered pods from different pod positions derived from the UDP method was presented in Figure $2 b$.

\subsection{The undetached whole-stem method (UWS)}

The UWS method provides a lower average percentage of pod shattering than those of DP and UDP methods (Table 3). The pattern of pod shattering in three different parts at $30{ }^{\circ} \mathrm{C}$ and $40^{\circ} \mathrm{C}$ were similar between UDP and UWS methods, namely very resistant $(0 \%$ shattering). The shattering degree was more varied at $50{ }^{\circ} \mathrm{C}$ and $60{ }^{\circ} \mathrm{C}$. At $50{ }^{\circ} \mathrm{C}$, the pod shattering in the upper part resulted in fourteen very resistant genotypes. However, the number of very resistant genotypes was reduced to eleven (in the middle part), and five genotypes (in the lower part). At $60{ }^{\circ} \mathrm{C}$, the pod shattering percentage of the upper, middle, and lower parts ranged from $0-63 \%, 2-67 \%$, and $0-77 \%$, respectively. The average of pod-shattering from sixteen genotypes at the upper, middle, and lower parts of the stem was presented in Figure 1c.

In the upper part, the pod shattering of 16 genotypes at $60{ }^{\circ} \mathrm{C}$ was categorized into six very resistant genotypes, eight resistant genotypes, one susceptible genotype, and one very susceptible genotype. The pod shattering in the middle part, the genotypes were classified into thirteen resistant genotypes, one moderate, one susceptible, and one very susceptible genotype. Meanwhile, in the lower part, the average of shattering increased, and the genotypes were categorized into one very resistant, seven resistant, six moderate, one susceptible, and one very susceptible genotype. The total average of pod-shattering from the upper, middle, and lower parts in the end observation $\left(60^{\circ} \mathrm{C}\right)$ resulted in seven genotypes with high consistent resistance (very resistant and resistant). The example of shattered pods from different pod positions derived from the UWS method was presented in Figure 2c.

\subsection{The effect of pod position}

The pod development on soybean was initiated at the first node of each soybean stem. The soybean pod develops at each node from the upper part to the lower part of the stem. In this research, the relationship between pod-shattering with three different pod positions in the stem was studied using three methods. Each of these pod position patterns not only describes the differences in podshattering from each part (upper, middle, and lower part) but also shows the different degrees of pod-shattering from the three methods (Figure 3).

The DP method provides the highest average degree of pod shattering at all three different pod positions (15\%) than the UDP (13\%) and UWS (11\%) methods. The UDP method provides the highest degree of pod shattering than the UWS method. When we observe the pod shattering based 
on the pod position on the stem of all methods, it showed that the pods at the lower position have the highest degree of shattering than those of the middle and upper parts.

In the DP method, the average shattering at the end of observation (after being subjected to $60^{\circ} \mathrm{C}$ ) in the upper, middle, and lower parts were $9 \%, 15 \%$, and $22 \%$, respectively. In the UDP as well as UWS methods, the pattern was similar. The lowest shattering was in the upper part $(8 \%$ and $7 \%$, respectively), followed by the middle (12\% and $11 \%$, respectively), and the lower part (19\% and $15 \%$, respectively).

The correlation among DP, UDP, and UWS methods using Pearson's correlation showing positive significant correlations among them (DP and UDP, $r=0.98^{* *}$; DP and UWS, $r=0.98^{* *}$, UDP and UWS, $\mathrm{r}=0.99^{* *}$ ).

Table 1. Pod shattering of three different pod positions on the plant-based on the detached pod (DP) method

\begin{tabular}{|c|c|c|c|c|c|c|c|c|c|c|c|c|c|}
\hline \multirow[t]{3}{*}{ No } & \multirow{3}{*}{ Genotype } & \multicolumn{12}{|c|}{ Pod shattering (\%) } \\
\hline & & \multicolumn{4}{|c|}{ Upper part $\left({ }^{\circ} \mathrm{C}\right)$} & \multicolumn{4}{|c|}{ Middle part $\left({ }^{\circ} \mathrm{C}\right)$} & \multicolumn{4}{|c|}{ Lower part $\left({ }^{\circ} \mathrm{C}\right)$} \\
\hline & & 30 & 40 & 50 & 60 & 30 & 40 & 50 & 60 & 30 & 40 & 50 & 60 \\
\hline 1 & Anj/G100H-6 & 0 & 0 & 0 & 3 & 0 & 0 & 0 & 16 & 0 & 0 & 0 & 18 \\
\hline 2 & Anj/G100H-14 & 0 & 0 & 0 & 3 & 0 & 0 & 0 & 20 & 0 & 0 & 0 & 20 \\
\hline 3 & Anj/G100H-16 & 0 & 0 & 0 & 0 & 0 & 0 & 0 & 12 & 0 & 0 & 0 & 18 \\
\hline 4 & Anj/G100H-21 & 0 & 0 & 0 & 0 & 0 & 0 & 0 & 15 & 0 & 0 & 0 & 25 \\
\hline 5 & Anj/G100H-24 & 0 & 0 & 0 & 2 & 0 & 0 & 0 & 4 & 0 & 0 & 0 & 13 \\
\hline 6 & Anj/G100H-28 & 0 & 0 & 0 & 2 & 0 & 0 & 0 & 5 & 0 & 0 & 0 & 5 \\
\hline 7 & Anj/G100H-44 & 0 & 3 & 2 & 2 & 0 & 0 & 0 & 3 & 0 & 0 & 0 & 6 \\
\hline 8 & Anj/IAC100-19 & 0 & 0 & 0 & 3 & 0 & 0 & 0 & 7 & 0 & 2 & 2 & 15 \\
\hline 9 & Anj/Rjbs-304 & 0 & 0 & 17 & 2 & 0 & 0 & 0 & 2 & 0 & 2 & 2 & 4 \\
\hline 10 & Anj/Rjbs-305 & 0 & 0 & 2 & 5 & 0 & 0 & 0 & 8 & 0 & 2 & 2 & 12 \\
\hline 11 & Anj/Rjbs-306 & 0 & 0 & 0 & 2 & 0 & 0 & 0 & 3 & 0 & 0 & 0 & 2 \\
\hline 12 & Anj/Rjbs-309 & 0 & 0 & 0 & 3 & 0 & 0 & 0 & 5 & 0 & 0 & 0 & 17 \\
\hline 13 & Anj/ Rjbs-311 & 0 & 0 & 0 & 0 & 0 & 0 & 0 & 5 & 0 & 0 & 0 & 27 \\
\hline 14 & Grbg/Anj-2 & 0 & 0 & 0 & 15 & 0 & 0 & 20 & 25 & 0 & 0 & 60 & 70 \\
\hline 15 & Dega 1 & 0 & 5 & 100 & 100 & 0 & 5 & 67 & 100 & 0 & 3 & 100 & 100 \\
\hline 16 & Detap 1 & 0 & 0 & 0 & 1 & 0 & 0 & 0 & 5 & 0 & 2 & 2 & 3 \\
\hline
\end{tabular}


Table 2. Pod shattering of three different pod positions on the plant-based on the undetached pod (UDP) method

\begin{tabular}{|c|c|c|c|c|c|c|c|c|c|c|c|c|c|}
\hline \multirow[t]{3}{*}{ No } & \multirow[t]{3}{*}{ Genotype } & \multicolumn{12}{|c|}{ Pod shattering (\%) } \\
\hline & & \multicolumn{4}{|c|}{ Upper part $\left({ }^{\circ} \mathrm{C}\right)$} & \multicolumn{4}{|c|}{ Middle part $\left({ }^{\circ} \mathrm{C}\right)$} & \multicolumn{4}{|c|}{ Lower part $\left({ }^{\circ} \mathrm{C}\right)$} \\
\hline & & 30 & 40 & 50 & 60 & 30 & 40 & 50 & 60 & 30 & 40 & 50 & 60 \\
\hline 1 & Anj/G100H-6 & 0 & 0 & 0 & 0 & 0 & 0 & 0 & 7 & 0 & 0 & 0 & 17 \\
\hline 2 & Anj/G100H-14 & 0 & 0 & 0 & 4 & 0 & 0 & 0 & 2 & 0 & 0 & 0 & 13 \\
\hline 3 & Anj/G100H-16 & 0 & 0 & 0 & 0 & 0 & 0 & 0 & 4 & 0 & 0 & 0 & 14 \\
\hline 4 & Anj/G100H-21 & 0 & 0 & 0 & 0 & 0 & 0 & 0 & 13 & 0 & 0 & 0 & 17 \\
\hline 5 & Anj/G100H-24 & 0 & 0 & 0 & 0 & 0 & 0 & 0 & 7 & 0 & 0 & 0 & 13 \\
\hline 6 & Anj/G100H-28 & 0 & 0 & 0 & 0 & 0 & 0 & 0 & 3 & 0 & 0 & 0 & 4 \\
\hline 7 & Anj/G100H-44 & 0 & 0 & 0 & 2 & 0 & 0 & 0 & 3 & 0 & 0 & 0 & 3 \\
\hline 8 & Anj/IAC100-19 & 0 & 0 & 0 & 0 & 0 & 0 & 0 & 3 & 0 & 0 & 0 & 14 \\
\hline 9 & Anj/Rjbs-304 & 0 & 0 & 0 & 3 & 0 & 0 & 0 & 2 & 0 & 0 & 0 & 4 \\
\hline 10 & Anj/Rjbs-305 & 0 & 0 & 0 & 0 & 0 & 0 & 0 & 0 & 0 & 0 & 0 & 7 \\
\hline 11 & Anj/Rjbs-306 & 0 & 0 & 0 & 0 & 0 & 0 & 0 & 3 & 0 & 0 & 0 & 3 \\
\hline 12 & Anj/Rjbs-309 & 0 & 0 & 0 & 7 & 0 & 0 & 0 & 3 & 0 & 0 & 0 & 13 \\
\hline 13 & Anj/ Rjbs-311 & 0 & 0 & 0 & 0 & 0 & 0 & 0 & 17 & 0 & 0 & 0 & 23 \\
\hline 14 & Grbg/Anj-2 & 0 & 0 & 0 & 33 & 0 & 0 & 0 & 40 & 0 & 0 & 13 & 58 \\
\hline 15 & Dega 1 & 0 & 0 & 63 & 77 & 0 & 0 & 67 & 73 & 0 & 0 & 60 & 100 \\
\hline 16 & Detap 1 & 0 & 0 & 0 & 0 & 0 & 0 & 0 & 4 & 0 & 0 & 0 & 7 \\
\hline
\end{tabular}

Table 3. Pod shattering of three different pod positions on the plant-based on the undetached whole-stem (UWS) method

\begin{tabular}{|c|c|c|c|c|c|c|c|c|c|c|c|c|c|}
\hline \multirow[t]{3}{*}{ No } & \multirow[t]{3}{*}{ Genotype } & \multicolumn{12}{|c|}{ Pod shattering (\%) } \\
\hline & & \multicolumn{4}{|c|}{ Upper part $\left({ }^{\circ} \mathrm{C}\right)$} & \multicolumn{4}{|c|}{ Middle part $\left({ }^{\circ} \mathrm{C}\right)$} & \multicolumn{4}{|c|}{ Lower part $\left({ }^{\circ} \mathrm{C}\right)$} \\
\hline & & 30 & 40 & 50 & 60 & 30 & 40 & 50 & 60 & 30 & 40 & 50 & 60 \\
\hline 1 & Anj/G100H-6 & 0 & 0 & 0 & 3 & 0 & 0 & 0 & 4 & 0 & $\overline{0}$ & 2 & 14 \\
\hline 2 & Anj/G100H-14 & 0 & 0 & 0 & 0 & 0 & 0 & 3 & 4 & 0 & 0 & 3 & 10 \\
\hline 3 & Anj/G100H-16 & 0 & 0 & 0 & 0 & 0 & 0 & 0 & 2 & 0 & 0 & 0 & 12 \\
\hline 4 & Anj/G100H-21 & 0 & 0 & 0 & 0 & 0 & 0 & 0 & 5 & 0 & 0 & 0 & 13 \\
\hline 5 & Anj/G100H-24 & 0 & 0 & 0 & 2 & 0 & 0 & 0 & 10 & 0 & 0 & 0 & 8 \\
\hline 6 & Anj/G100H-28 & 0 & 0 & 0 & 3 & 0 & 0 & 0 & 2 & 0 & 0 & 0 & 4 \\
\hline 7 & Anj/G100H-44 & 0 & 0 & 3 & 1 & 0 & 0 & 0 & 3 & 0 & 0 & 2 & 4 \\
\hline 8 & Anj/IAC100-19 & 0 & 0 & 0 & 3 & 0 & 0 & 0 & 12 & 0 & 0 & 3 & 13 \\
\hline 9 & Anj/Rjbs-304 & 0 & 0 & 0 & 3 & 0 & 0 & 2 & 3 & 0 & 0 & 1 & 2 \\
\hline 10 & Anj/Rjbs-305 & 0 & 0 & 0 & 0 & 0 & 0 & 2 & 5 & 0 & 0 & 2 & 8 \\
\hline 11 & Anj/Rjbs-306 & 0 & 0 & 0 & 2 & 0 & 0 & 0 & 6 & 0 & 0 & 0 & 0 \\
\hline 12 & Anj/Rjbs-309 & 0 & 0 & 0 & 0 & 0 & 0 & 2 & 8 & 0 & 0 & 5 & 10 \\
\hline 13 & Anj/ Rjbs-311 & 0 & 0 & 0 & 2 & 0 & 0 & 0 & 7 & 0 & 0 & 2 & 15 \\
\hline 14 & Grbg/Anj-2 & 0 & 0 & 0 & 27 & 0 & 0 & 0 & 33 & 0 & 0 & 2 & 43 \\
\hline 15 & Dega 1 & 0 & 0 & 63 & 63 & 0 & 0 & 67 & 67 & 0 & 0 & 67 & 77 \\
\hline 16 & Detap 1 & 0 & 0 & 0 & 0 & 0 & 0 & 0 & 2 & 0 & 0 & 2 & 4 \\
\hline
\end{tabular}

The shattering degree:

\begin{tabular}{|l|l|l|l|}
\hline & Very resistant & & Moderate \\
\hline & Resistant & & Susceptible \\
\hline & & & Very susceptible \\
\hline
\end{tabular}




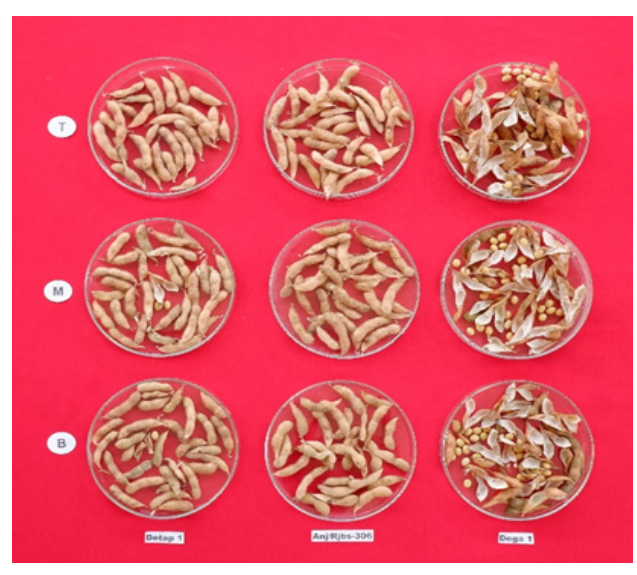

(a)

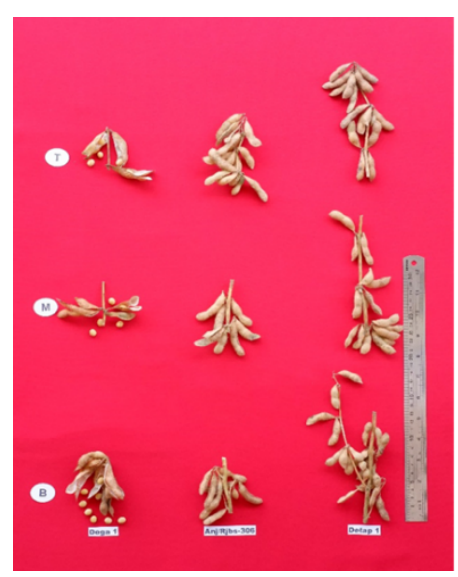

(b)

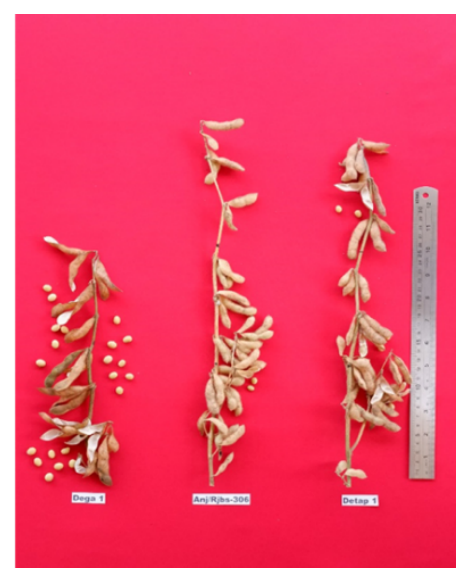

(c)

Fig. 1. The example of shattered pods from different pod positions $(\mathrm{T}=$ upper, $\mathrm{M}=$ middle, $\mathrm{B}=$ lower part) derived from the detached pod (DP) method (a), undetached pod (UDP) method (b), and undetached whole-stem (UWS) method (c). Left to the right: Dega 1, Anj/Rjbs-306, Detap 1

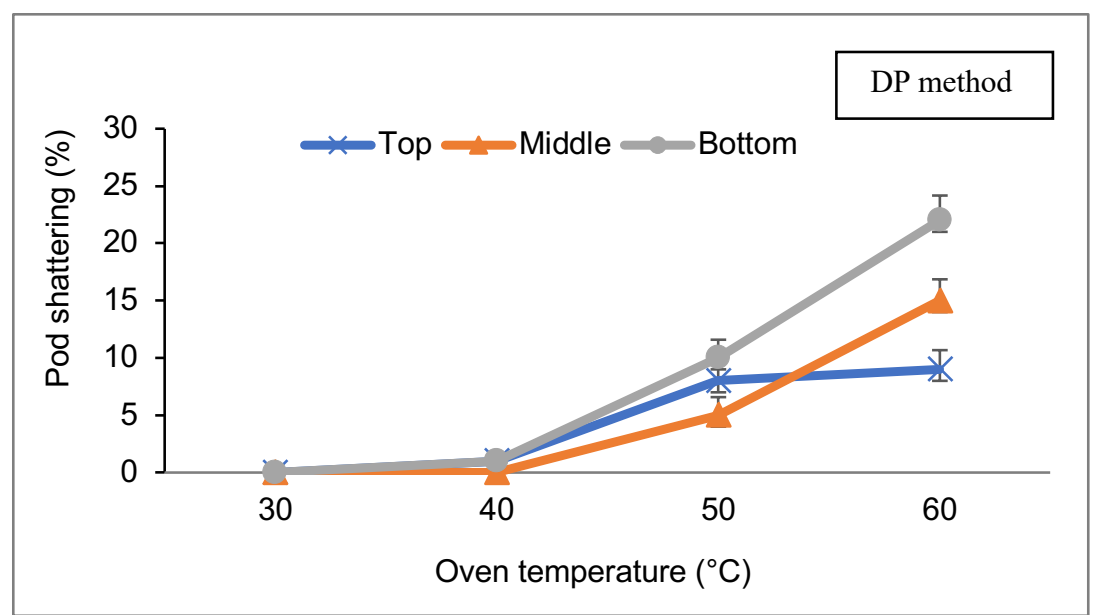

(a)

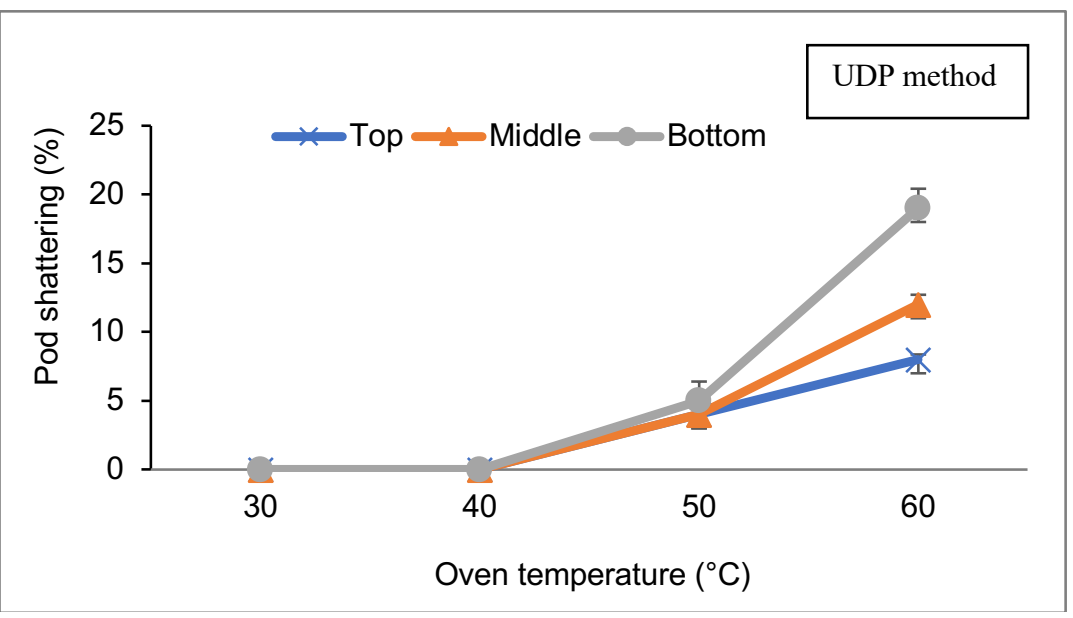

(b) 


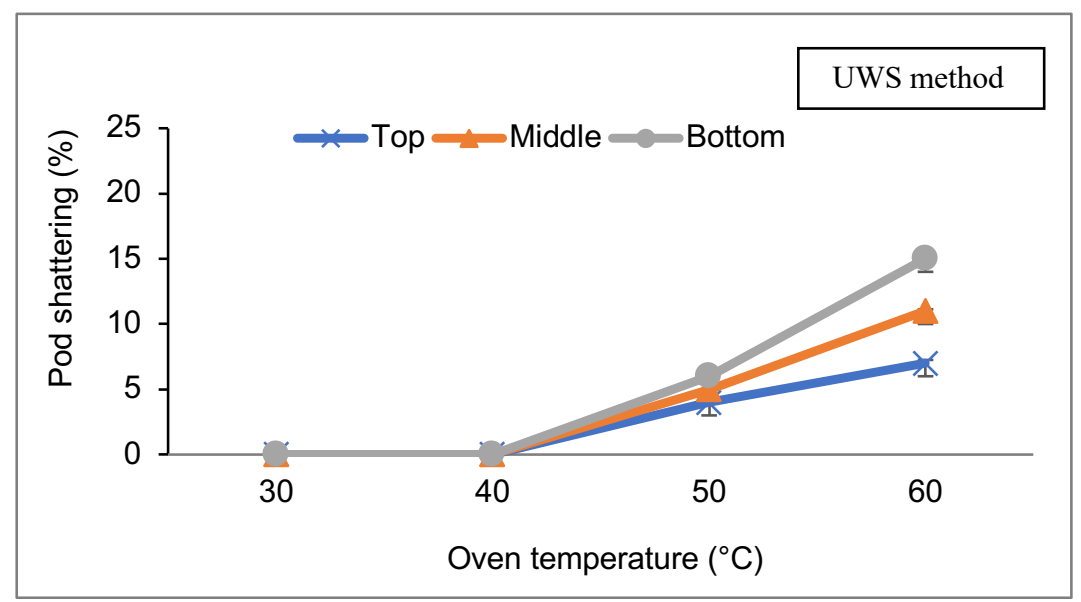

(c)

Fig. 2. The average of pod shattering (\%) at an oven temperature of $30{ }^{\circ} \mathrm{C}, 40{ }^{\circ} \mathrm{C}, 50{ }^{\circ} \mathrm{C}$, and 60 ${ }^{\circ} \mathrm{C}$ from 16 soybean genotypes in the upper, middle and lower part of the stem, based on the detached pod (DP) method (a), undetached pod (UDP) method (b), and undetached whole-stem

(UWS) method (c)

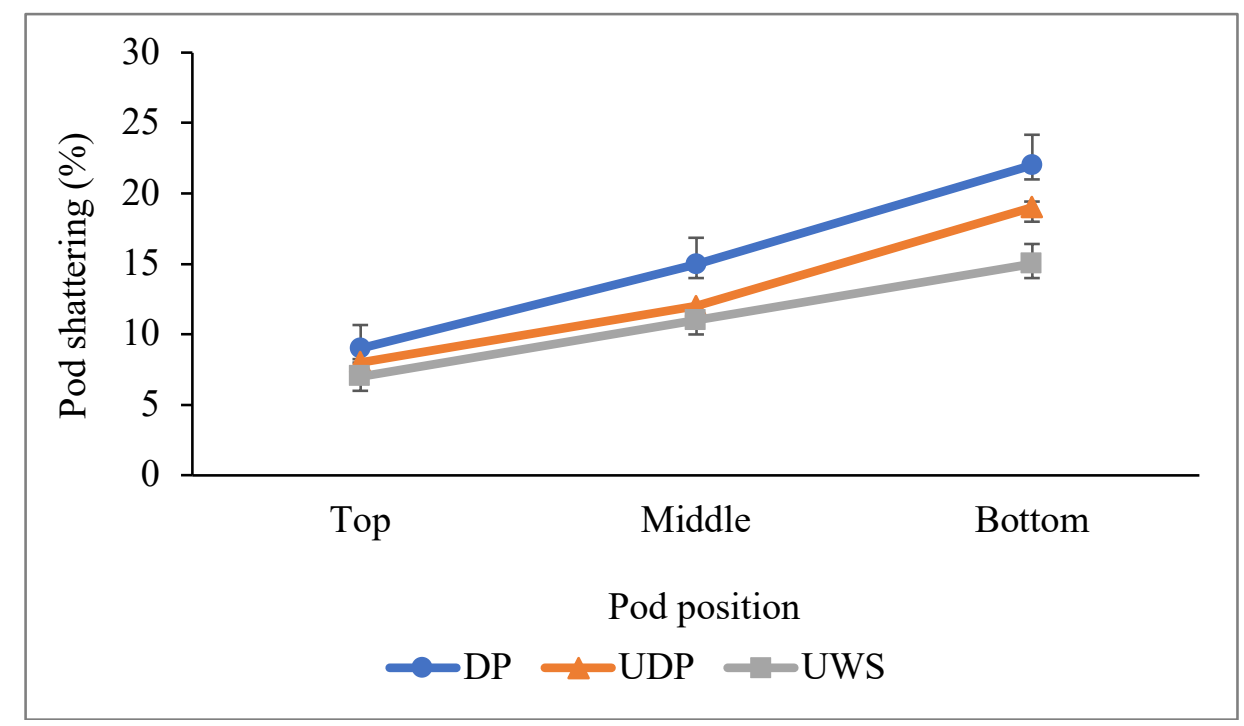

Fig. 3. The pod-shattering based on the three methods at three different pod positions in the stem

\subsection{The determinant for pod shattering resistance}

The pod and seed morphological characters, the pod wall weight to pod weight ratio (PTT), seed weight to pod weight ratio (STT), and the weight of 25 seeds (WSE) varied from the three pod positions on the stem. The characteristic of pod size on the upper part was generally higher than those on the middle and lower parts, and it was also followed by the degree of pod shattering which was lower in the upper part than those of the middle and lower parts. 
The backward stepwise regression was used to select the most significant variables as the determinant factors of pod shattering resistance based on the ten variables (Table 4). In the DP method, the character of PTT was the most influential factor of shattering in all pod positions on the stem. This character also becomes an important factor in the UWS method. However, in the UDP method, the most important character of pod shattering in the upper and lower part of the stem was seed thickness (STH), meanwhile, the WSE was the variable that contributes most to the pod shattering in the middle part.

The character of PTT becomes a significant character for pod shattering resistance in most models. Interestingly, the regression coefficient value of PTT was also consistently higher than other characters, which implied that this character was the most influential factor on the pod shattering resistance.

A measurement of the strength of the association between pod-shattering with the pod and seed characters in the DP, UDP, and UWS methods was conducted using Pearson correlation (Figure 4). In the DP method (Figure 4a), pod shattering was significantly correlated with PLG (pod length), PWD (pod width), SLG (seed length), STH (seed width), PTT, STT, and WSE. In the DP method (Figure 4b), pod shattering was significantly correlated with PLG, SWD, and WSE. In the UWS method (Figure 4c), pod shattering was significantly correlated with almost all pod and seed traits, except PTH, SWD, and STT. In this study, the results from the stepwise regression were mostly in line with the correlation analysis.

Table 4. The final step of backward stepwise regression

\begin{tabular}{llll}
\hline \multirow{2}{*}{$\begin{array}{l}\text { Metho } \\
\text { d }\end{array}$} & \multicolumn{1}{c}{ Upper } & \multicolumn{1}{c}{ Mod position on the stem } \\
\hline DP & $Y=-193.6+$ & $Y=-174.2+$ & \multicolumn{1}{c}{ Lower } \\
& $5.70 S W D+2.13 S T H+$ & $2.16 P H G+176 P T T$ & $Y=-210.4+$ \\
& $158 P T T$ & & $2.50 P H G-5.90 S T H+$ \\
& & & $250 P T T$ \\
\hline UDP & $Y=-54.69+10.0 S T H$ & $Y=-12.180+3.0 W S E$ & $Y=-2.417+$ \\
& & & $0.69 P L G-1.78 P W D-$ \\
& & & $7.40 P T H+13.50 S W D-$ \\
& & $Y=253.0+1.12 P H G-$ & $Y .30 S T H$ \\
\hline UWS & $Y=-495.6+$ & $90 P T T-169 S T T+$ & $4.60 S L G+215 P T T+$ \\
& $2.60 S L G+260 P T T+$ & $1.59 W S E$ & $290 S T T$ \\
\hline
\end{tabular}

$\mathrm{DP}=$ detached pod, UDP $=$ undetached pod, UWS $=$ undetached whole-stem, PLG = pod length, $\mathrm{PWD}=$ pod width, $\mathrm{PHG}=$ width at mid part, $\mathrm{PTH}=$ pod thickness, $\mathrm{SLG}=$ seed length, $\mathrm{SWD}=$ seed width, STH = seed thickness, PTT = pod wall weight to pod weight ratio, $\mathrm{STT}=$ seed weight to pod weight ratio, WSE = weight of 25 seeds 


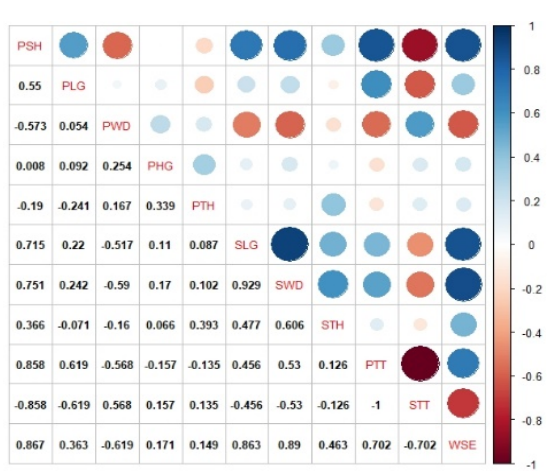

(a)

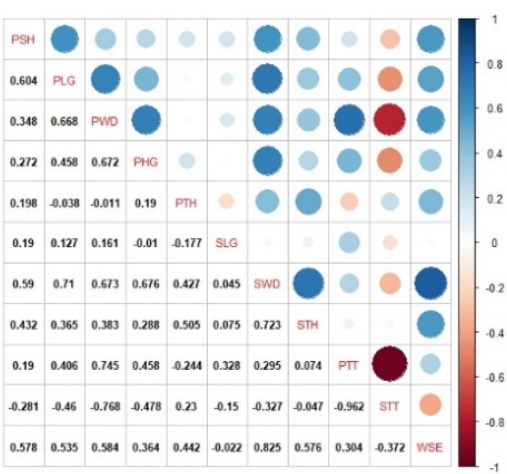

(b)

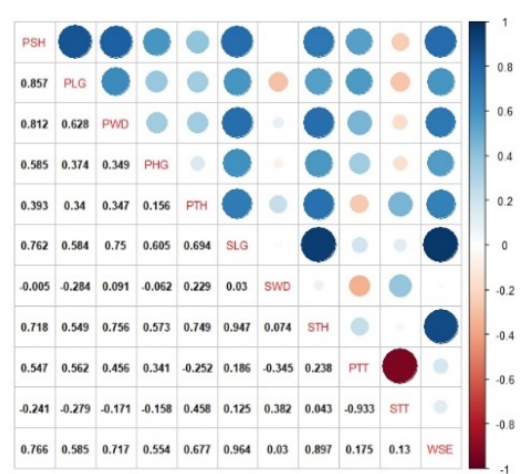

(c)

Fig. 4. The Pearson's correlation analysis using R program between pod-shattering with pod and seed characters in the detached pod method (a), undetached pod method (b), and undetached whole-stem method (c). PSH = pod shattering, $\mathrm{PLG}=$ pod length, $\mathrm{PWD}=$ pod width, $\mathrm{PHG}=$ width at mid part, PTH = pod thickness, SLG = seed length, SWD = seed width, STH = seed thickness, PTT $=$ pod wall weight to pod weight ratio, $\mathrm{STT}=$ seed weight to pod weight ratio, WSE $=$ weight of 25 seeds. The darker color indicates the stronger relationship, with the magnitude limit of significance $> \pm 0.5$

\section{Discussion}

The yield loss due to pod shattering has become a significant problem in food crops as well as horticultural crops. In soybean, pod shattering contributed to the significant yield loss in the tropics and subtropics. In Indonesia, soybeans are planted at the beginning of the dry season, and thus the early stage of maturity will be at the peak of the dry season. These hot and dry environmental conditions trigger the occurrence of pod shattering.

This research study was conducted in Banyuwangi which has a maximum annual temperature of $30^{\circ} \mathrm{C}$. Since the pod shattering was also affected by environmental factors (Tukamuhabwa et al., 2002; Adeyeye et al., 2014), hence this study used the oven-dry method as the simulation of the field shattering screening. The use of the oven-dry method provides some advantages, this approach offers the benefit of more genotypes being tested, and the research environment is homogeneous. This method also may result in a genotype of high shatter resistance. Furthermore, the use of the oven temperature treatments of $50^{\circ} \mathrm{C}$ and $60^{\circ} \mathrm{C}$ could differentiate the pod shattering resistance among genotypes (Krisnawati et al., 2020). Therefore, the oven-dry method was widely applied in the screening for pod shattering resistance in the various centers of soybean production in the world (AVRDC, 1979; IITA, 1986; Tukamuhabwa et al., 2002; Mohammed et al., 2014; Bhor et al., 2014).

In this study, the evaluation of the pod shattering resistance of each genotype using the detached pod method resulted in a higher pod-shattering percentage than the undetached pod methods. It means that the shattering assessment using the detached pod method provides a higher selection pressure. The result of this study showed that resistant genotypes in the detached pod method (Anj/G100H-44 and Anj/Rjbs-304) were also shown to be consistently resistant in the undetached pod methods. This result was supported by the significant correlation among the three 
methods. A screening for shattering resistance in soybean by Girase et al. (2018) using the ovendry method (HOA, hot air oven method) and natural field method also resulted in a consistent result between these two methods. A previous study by Tiwari \& Bhatnagar (1991) reported that the detached pod method with oven drying was highly correlated with field shattering.

The pod position on the plant needs to be studied not only to reveal the pod shattering pattern but also to have implications for the character of the seed size. In this study, the pods at the upper part of the stem had larger seeds and also had a lower shattering percentage than those of pods at the middle and lower part of the stem. Similarly, Ghassemi-Golezani et al. (2012) found that seeds of upper parts of the canopies were larger compared with those of middle and lower parts. According to Illipronti et al. (2000), the large seed size in the upper part of the stem might be partly attributable to a higher light interception by the upper leaves and pods. In addition, the variability of seed characters of soybean cultivars was attributed to differences in their genetic constitution.

So far, little is known about the relationship between the pod positions on the plant with the pod shattering resistance. Based on this study, the evaluation for the distribution of pod shattering due to differences in the pod position in the stem showed that the shattering percentage of pods at the lower part of the stem was the highest, followed by pods at the middle part and upper part, respectively. This pattern was consistent in all methods. It also can be seen that soybean genotypes that were classified as resistant to pod shattering showing a resistant degree for pods at the lower part. A study by Krisnawati \& Adie (2017b) using the oven method and ambient temperature method obtained a similar result that pods position at the lower part was more susceptible to pod shattering than those in the middle and upper parts. The difference in the shattering at various pod positions on the stem is related to the differences in pod maturity levels in each plant. Periods of flowering and pod development at individual nodes are almost as long and continue for up to 30 days (Egli \& Buerning, 2006). Soybeans start flowering at the lower nodes of the stem and flower progressively up the stem (Hanway \& Thompson, 1967; Saitoh et al., 1998), hence the pods that develop at the earliest flower may age more than the pods at the middle- and upper-part positions. On indeterminate cultivars, flowers at the top nodes of the main stem open after those on the lower stem. Meanwhile, in the determinate cultivars, pod development on main stems and branches occurred at approximately the same time (Munier-Jolain et al., 1994; Egli \& Buerning, 2002).

According to Romkaew et al., (2007), the relationship between pod shattering and the pod position in the stem was also affected by the moisture content of the pods. In other crops, such as mungbean, it also showed that the indeterminate flowering habit of this crop contributes to the spread of flowering and pod maturity over the entire reproductive phase on a single plant. As a result, pods that develop at the earliest flower may shatter before $100 \%$ pod maturity (Vairam et al., 2017).

In this study, the assessment of the relationship between the seed and pod morphological characters with pod-shattering at different pod positions on the stem was using the backward stepwise regression analysis. The use of stepwise regression can extract one or a group of variables that contribute the most to the dependent character. We use the backward stepwise analysis in 
which all variables are included in the model and then, each step, the variables that contribute less to the dependent variable (in this case is pod-shattering) are eliminated. The DP and UWS methods showed a consistent pattern for the determinant factor of pod shattering resistance, namely the pod wall weight to the pod weight ratio. However, in the UDC method, the seed thickness becomes the most influential factor of pod shattering in the upper and lower part of the stem, meanwhile, the weight of 25 seeds was the most important factor of the pod shattering in the middle part.

The relationship between pod-shattering with the pod and seed characters in the DP, UDP, and UWS methods, which were investigated using Pearson correlation analysis, showed that each method has a different result. However, five pod and seed characters in most all methods showed a consistently significant positive correlation with pod shattering, namely pod length, seed length, seed weight, pod wall weight to the pod weight ratio, and weight of 25 seeds. In this study, pod length was an important pod character in the pod shattering resistance. Our result was in agreement with previous studies (Krisnawati \& Adie, 2017b; Krisnawati et al., 2019; Krisnawati et al., 2020). A longer pod means that the longer the pod suture, which makes it easier for the pods to open. Furthermore, a higher value of seed length, seed thickness, and seed weight showing the higher pod shattering. Those seed characters represent the pod size. These findings are in agreement with previous studies (Bara et al., 2013), who reported that genotype with small pod was tolerant to pod shattering.

The pod wall weight to pod weight ratio might represent the thickness of the pod wall and/or the pod size. A higher ratio of pod wall weight to pod weight may be assumed to result in a thinner pod wall and/or could be a smaller pod size, and vice versa. The relationship between pod wall thickness and pod size with pod-shattering has been investigated in several studies. Tiwari \& Bhatia (1995) reported that the pod-wall thickness was found to be significantly negatively correlated with the degree of pod shattering. Similarly, Krisnawati \& Adie (2017c) found the highest direct effects of the pod wall thickness on the pod shattering, suggesting that this character was one of the important contributors to the pod shattering resistance. In Brassica napus, the pod wall weight was also closely related to the pod shattering which affects by regulating the total hemicellulose amount in the pod walls (Kuai et al., 2016).

The pod-shattering degree of sixteen genotypes in this study was varied. The shattering degree was based on the observation after subjection to an oven temperature of $60{ }^{\circ} \mathrm{C}$. Five genotypes (Anj/G100H-28, Anj/G100H-44, Anj/Rjbs-304, Anj/Rjbs-305) and check cultivar Detap 1 showed resistance to pod shattering based on the three methods. Nowadays, high yielding and shatter resistance cultivars were some of the consumer's preferences worldwide. It is important to consider consumer preferences in cultivar selection or breeding (Rabadan et al., 2019). Hence, those four lines need to be tested for their yield potential to be further utilized for large-scale development, or directly used as donor parents for shattering resistance in the breeding program. 


\section{Conclusion}

The detached pod and undetached pod methods provide a consistent result for the evaluation of pod shattering resistance. The detached pod method with oven-dry was suggested to be used for screening of pod shattering resistance due to enables to screen genotypes in greater numbers, provides a homogeneous selection pressure and environmental condition. Pods at the upper part of the stem were more resistant to shattering than those of pods in the middle part and lower part, respectively. The pod length, seed length, seed weight, pod wall weight to the pod weight ratio, and weight of 25 seeds were the influential factors in the pod shattering resistance. The three shattering evaluation methods resulted in five genotypes (Anj/G100H-28, Anj/G100H-44, Anj/Rjbs-304, Anj/Rjbs-30, and Detap 1) with consistent resistance to pod shattering.

\section{ACKNOWLEDGEMENTS}

The authors acknowledge the Indonesian Agency for Agricultural Research and Development (IAARD), Ministry of Agriculture, for the financial support under Project No. 849/Kpts/KP.320/H.1/9/2019.

\section{References}

Adeyeye, A.S., Togun, A.O., Akanbi, W.B., Adepoju, I.O. \& Ibirinde, D.O. (2014). Pod shattering of different soybean varieties, Glycine $\max (\mathrm{L})$ Merrill, as affected by some growth and yield parameters. The International Journal of Agricultural Policy and Research, 2: 10-15.

Agrawal, A.P., Basarkar, P.W., Salimath, P.M. \& Patil, S.A. (2002). Role of cell walldegrading enzymes in pod shattering process of soybean Glycine max (L) Merrill. Current Science, 82: 58-61.

AVRDC (Asian Vegetable Research and Development Centre). (1979). Soybean Report. Shanhwa, Taiwan, Republic of China.

Bara, N., Khare, D. \& Srivastava, A.N. (2013). Studies on the factors affecting pod shattering in soybean. The Indian Journal of Genetics and Plant Breeding, 73: 270-277.

Bhor, T.J., Chimote, V.P. \& Deshmukh, M.P. (2014). Inheritance of pod shattering in soybean [Glycine max (L.) Merrill]. Electronic Journal of Plant Breeding, 5: 671-676.

Cavalieri, A., Lewis, D.W., Gulden, R.H. (2014). Pod drop and pod shatter are not closely related in canola. Crop Science, 54: 1184-1188.

Egli, D.B., Bruening, W.P. (2002). Synchronous flowering and fruit set at phloem isolated nodes in soybean. Crop Science, 42: 1535-1540. 
Egli, D.B., Bruening, W.P. (2006). Temporal profiles of pod production and pod set in soybean. European Journal of Agronomy, 24: 11-18.

Fehr, W.R. \& Caviness, C.E. (1977). Stages of soybean development. Special Report No. 80. Iowa State University, Ames, IA.

Funatsuki, H., Suzuki, M., Hirose, A., Inaba, H., Yamada, T., Hajika, M., Komatsu, K., Katayama, T., Sayama, T., Ishimoto, M. \& Fujino, K. (2014). Molecular basis of a shattering resistance boosting global dissemination of soybean. PNAS, 111: 17797-17802.

Ghassemi-Golezani, K., Lotfi, R. \& Norouzi, M. (2012). Seed quality of soybean cultivars affected by pod position and water stress at reproductive stages. IJPAES, 2: 119-125.

Girase, V.S., Khedkar, D.J., Rajmane, V.B. \& Deokar, S.D. (2018). Evaluation of soybean germplasm for shattering resistance. International Journal of Chemical Studies, 6: 2854-2858.

Hradilová, I., Trněný, O., Válková, M., Cechová, M., Janská, A., Prokešová, L., Aamir, K., Krezdorn, N., Rotter, B., Winter, P., Varshney, R.K., Soukup, A., Bednář, P., Hanáček, P. \& Smýkal, P. (2017). A combined comparative transcriptomic, metabolomic, and anatomical analyses of two key domestication traits: pod dehiscence and seed dormancy in pea (Pisum sp.). Frontiers in Plant Science, 8: 542.

Hanway, J. J. \& Thompson, H.E. (1967). How a soybean plant develops. Spec. Rep. 53, Coop. Ext. Serv., Iowa State Univ., Ames, Iowa.

IITA [International Institute of Tropical Agriculture] (1986). A laboratory method for evaluating resistance to pod shattering in soybeans. Annual Report. IITA, Ibadan, Nigeria, pp. 5859.

Illipronti, R.A., Lommen, W.J.M., Langerak, C.J. \& Struik, P.C. (2000). Time of pod set and seed position on the plant contribute to variation in the quality of seeds within soybean seed lots. NJAS: Wageningen Journal of Life Sciences 48: 165-180.

Kataliko, R.K., Kimani P.M., Muthomi J.W., Wanderi W.S., Olubayo F.M. \& Nzuve F.M. (2019). Resistance and correlation of pod shattering and selected agronomic traits in soybeans. Journal of Plant Studies 8: 39-48.

Kibar, H. \& Ozturk, T. (2008). Physical and mechanical properties of soybean. International Agrophysics, 22: 239-244.

Krisnawati, A. \& Adie, M.M. (2017a). Identification of soybean genotypes for pod shattering resistance associated with agronomical and morphological characters. Biosaintifika, 9: 193-200.

Krisnawati, A. \& Adie, M.M. (2017b). Characterization and performance of agronomic characters of soybean genotypes resistant to pod shattering. Biodiversitas, 18: 1158-1164. 
Krisnawati, A. \& Adie, M.M. (2017c). Variability on morphological characters associated with pod shattering resistance in soybean. Biodiversitas, 18: 73-77.

Krisnawati, A., Adie, M.M., Soegianto, A., Waluyo, B. \& Kuswanto. (2019). Pod shattering resistance and agronomic traits in $\mathrm{F}_{5}$ segregating populations of soybean. SABRAO Journal of Breeding and Genetics, 51: 266-280.

Krisnawati, A., Soegianto, A., Waluyo, B. \& Kuswanto. (2020). The pod shattering resistance of soybean lines is based on the shattering incidence and severity. Czech Journal of Genetics and Plant Breeding, 56: 111-122.

Kuai, J., Sun, Y., Liu, T., Zhang, P.I., Zhou, M., Wu, J. \& Zhou, G. (2016). Physiological mechanisms behind differences in pod shattering resistance in rapeseed (Brassica napus L.) varieties. PLoS ONE, 11: e0157341.

Liu, X., Tu, B., Zhang, Q. \& Herbert, S.J. (2019). Physiological and molecular aspects of pod shattering resistance in crops. Czech Journal of Genetics and Plant Breeding 55: 87-92.

Mohammed, H., Akromah R., Abudulai M., Mashark S.A. \& Issah A. (2014). Genetic analysis of resistance to pod shattering in soybean. Journal of Crop Improvement, 28: 17-26.

Munier-Jolain, N.G., Ney, B. \& Duthion, C. (1994). Reproductive development of an indeterminate soybean as affected by morphological position. Crop Science 34: 1009-1013.

Philbrook B. \& Oplinger E.S. (1989). Soybean field losses as influenced by harvest delays. Agronomy Journal, 81: 251-258.

Rabadan, A., Alvarez-Orti, M. \& Pardo, J.E. (2019). Morphological, mechanical, and sensory properties of almond (Prunus dulcis L.) and pistachio (Pistacia vera L.) cultivars grown in Spain. Kuwait Journal of Science, 46: 103-113.

Romkaew J., Umezaki T., Suzuki K. \& Nagaya Y. (2007). Pod dehiscence about pod position and moisture content in soybean. Plant Production Science, 10: 292-296.

RStudio Team. (2020). R: A language and environment for statistical computing, R Foundation for Statistical Computing, Vienna, Austria. URL https://www.R-project.org/.

Saitoh, K., Isobe, S. \& Kuroda, T. (1998). Pod elongation and seed growth as influenced by nodal position on the stem and raceme order in a determinate type of soybean cultivar. Japanese Journal of Crop Science 67: 523-528.

Tiwari S.P. \& Bhatia V.S. (1995). Characterization of pod anatomy associated with resistance to pod-shattering in soybeans. Annals of Botany, 72: 483-85.

Tiwari S.P. \& Bhatnagar P.S. (1991). Pod shattering as related to other agronomic attributes in soybean. Tropical Agriculture, 68: 102-103. 
Tukamuhabwa, P., Dashiell, K.E., Rubaihayo, P. R. \& Nabasirye, M. (2002). Determination of field yield loss and effect of environment on pod shattering in soybean. African Crop Science Journal, 10: 203-209.

Vairam, N., Lavanya, S.A. \& Vanniarajan, C. (2017). Screening for pod shattering in the mutant population of mungbean (Vigna radiata (L.) Wilczek). Journal of Applied and Natural Science, 9: $1787-1791$.

Yue, J., Ma, Y.F. \& Gao, Q.Y. (2006). Pod shattering character in main soybean cultivars of Huang-Huai-Hai soybean region of China. Journal of Henan Agricultural Sciences, 35: 56-59.

Zhang, L. \& Bellalloui. (2012). Effects of planting dates on shattering patterns under early soybean production system. American Journal of Plant Sciences, 3: 119-124.

Zhang, L. \& Boahen, L. (2010). Evaluation of critical shattering time of early maturity soybeans under early soybean production system. Agriculture and Biology Journal of North America, 1: 440-447.

Zhang, Q., Tu, B., Liu, C. \& Liu, X. (2018). Pod anatomy, morphology, and dehiscing forces in pod dehiscence of soybean (Glycine $\max$ (L.) Merrill). Flora, 248: 48-53.

Zheng, S., Maeda, A. \& Fukuyama, M. (2003). Genotypic and environmental variation of lag period of pod growth in soybean. Plant Production Science, 6: 243-246.

Submitted: $26 / 10 / 2020$

Revised: $01 / 03 / 2021$

Accepted: 09/05/2021

DOI: $10.48129 / \mathrm{kjs} . v 49 \mathrm{i} 1.10835$ 